\title{
Características físicas e químicas de grãos verdes de linhagens e cultivares de feijão caupi para processamento tipo conserva ${ }^{1}$
}

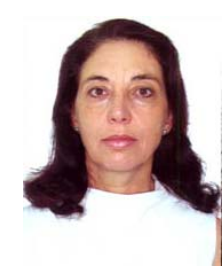

Eliza D. P. de A. Lima², Edlene de S. Jerônimo ${ }^{4}$, Carlos A. de A. Lima², Perla J. de S. Gondim4, Mauro L. Aldrigue ${ }^{3} \&$ Lourival F. Cavalcante ${ }^{2}$

\footnotetext{
1 Parte do Trabalho de Graduação do segundo autor

2 Departamento de Solos e Engenharia Rural/CCA/UFPB. E-mail:epozzob@terra.com.br (Foto)

${ }^{3}$ Departamento de Tecnologia e Química de Alimentos/CT/UFPB

${ }^{4}$ Engenheiro Agrônomo
}

Protocolo 5 - 11/1/2002 - Aprovado em 17/2/2003

\begin{abstract}
Resumo: O objetivo deste trabalho foi estudar a viabilidade da introdução de dez linhagens e duas cultivares de feijão caupi verde para processamento tipo conserva. O processamento iniciou-se pelo debulhamento, branqueamento dos grãos e acondicionamento nos frascos de vidro. Para qualificar os doze lotes de grãos para conserva, foi verificado o grau de maturação de acordo com a coloração dos grãos, na sua totalidade verdes, obtidos com aproximadamente 30 a 40 dias após a floração. O tratamento térmico foi otimizado em $121^{\circ} \mathrm{C}$ com o tempo de esterilização de $6 \mathrm{~min}$. Foram realizados estudos físicos e químicos dos grãos verdes e processados, ressaltando-se o valor médio de proteínas entre 23,30 a 31,30\%, para grãos frescos, e 22,00 a 27,10\% para grãos processados, apresentando uma pequena perda de proteínas, em média de $7 \%$. Os valores de $\mathrm{pH}$ dos grãos frescos $(6,72$ a 6,90$)$ e dos grãos processados $(6,38$ a 6,60$)$ classificam este alimento como de baixa acidez. A absorção de água (\%) e a perda de água (\%) dos grãos, após o processamento, apresentaram grande variabilidade. As amostras das linhagens TE-87-108-6G, Linguagem Avançada, TE-90-180-88F e TE-92-199-20F apresentaram melhor aparência quanto à coloração dos grãos verdes acinzentado e do líquido de acondicionamento, em relação às demais amostras, proporcionando conservas com boas características técnicas.
\end{abstract}

Palavras-chave: Vigna unguiculata (L.) Walp., caracterização, processamento

\section{Physical and chemical characteristics of green grains of cowpea cultivars and lines for processing and preservation}

\begin{abstract}
The objective of this study was to observe viability of introduction of ten lines and two cultivars of green cowpea for processing and preservation. The preservation procedure started by diluting, pod bleaching and packing in glass recipients. To qualify the twelve lots of grains for preservation, the maturation degree was verified according to grain color, in its totality green, obtained approximately 30 to 40 days after flowering. The processing heat was optimized for $121{ }^{\circ} \mathrm{C}$ with the sterilization time of $6 \mathrm{~min}$. Physical and chemical studies of the green grains were accomplished and processed, the mean values of proteins were between 23.30 and $31.30 \%$ for fresh grains and 22.00 to $27.10 \%$ for processed grains presenting a small loss $(7 \%)$ of proteins. The values of $\mathrm{pH}$ of the fresh grains $(6.72$ to 6.90$)$ and that of processed grains $(6.38$ to 6.60) permit to classify this product as of low acidity. The absorption of water (\%) and the loss of water (\%) of the grains after the processing presented high variability. The samples of the lines TE-87-108-6G, Linguagem Avançada, TE-90-180-88F and TE-92-199-20F presented better appearance (green greyish) of grains and that of packing liquid in comparison to other samples, providing preservation with good technical characteristics.
\end{abstract}

Key words: Vigna unguiculata (L) Walp., characterization, processing

\section{INTRODUÇÃO}

O feijão caupi, também denominado feijão verde, feijãode-corda ou feijão macassar, é uma Dicotiledônea pertencente à ordem Rosales, família Leguminosae, subfamília Papilionoi- deae, tribo Phaseoleae, subtribo Phaseolinae, gênero Vigna, e à espécie Vigna unguiculata (Sellschop, 1962).

Esta leguminosa é uma das principais culturas exploradas pelos pequenos produtores da região Nordeste, por ser uma excelente fonte protéica, podendo ser utilizada para adubação 
verde, forrageira, capacidade de fixar nitrogênio e rusticidade, que lhe confere uma capacidade de suportar temperaturas elevadas e locais com limitações hídricas (Calegari, 1995).

Leguminosas geralmente são colhidas secas; entretanto, a colheita pode ser realizada após os grãos terem atingido o teor de sólidos para o qual estão geneticamente programados, no início da maturidade fisiológica. Desta forma, obtém-se grãos de coloração verde apreciável de considerada aceitabilidade, devido ao sabor suave e textura macia (Vieira, 1992).

A aceitabilidade de um alimento na dieta humana depende não apenas de sua qualidade nutricional mas, também, de suas características de cozimento, de hidratação e da qualidade do caldo produzido (Cazetta et al., 1995). Devendo o processo de enlatamento do grão, além de esterilizar o produto e eliminar os fatores antinutricionais, manter a aparência, o sabor e a textura adequada à preferência do consumidor (Germer et al.,1995; Quast \& Silva, 1977).

O feijão é muito sensível a alterações pós-colheita, no que se refere à sua qualidade de cocção e palatabilidade e, ao ser armazenado por mais de dois meses, os grãos adquirem coloração escura e de cocção mais difícil. Todos esses fatores dificultam a comercialização do produto (EMBRAPA, 1997).

$\mathrm{O}$ enlatamento de leguminosas garante o consumo na entressafra e proporciona economia de tempo e energia, visto que são necessárias até três horas a $100{ }^{\circ} \mathrm{C}$ para o cozimento de leguminosas, tais como a soja e o feijão, no ponto de maturação de colheita (Parsi-Ros et al., 1987).

O processo do grão fresco é uma forma de preservação da coloração verde característica e garante o consumo em qualquer época do ano, principalmente na entressafra (Islam \& Lea, 1979). O tratamento térmico, que proporciona uma intensidade satisfatória de esterilização, deverá ter como objetivo conservar as características nutricionais e sensoriais do produto (Abbatemarco \& Ramaswamy, 1994; Germer et al., 1995; Quast \& Silva, 1977).

Frente à disponibilidade e à viabilidade do consumo de leguminosas enlatadas, ainda no estádio verde e ausência de feijão caupi enlatados ou em frascos de vidros no mercado nacional, justificou-se a realização deste trabalho, que teve como objetivo avaliar os aspectos físicos e químicos de diferentes linhagens e cultivares dos grãos frescos, e pós-processados em frasco de vidro, avaliando-se os efeitos do processamento.

\section{MATERIAL E MÉTODOS}

\section{Matéria-prima}

Vagens no estádio verde de feijão caupi, com aproximadamente 30 a 40 dias após a floração de dez linhagens (TE-92-19920F, TE-90-170-29F, TE-90-170-76F, CNCX-405-17F, CNCX-40912-F, TE-90-180-10F, Linguagem Avançada, TE-87-108-6G, TE90-180-9F, TE-90-180-88F) e duas cultivares (IPA-206 e BR-02Bragança), cultivadas no Setor de Olericultura do Centro de Ciências Agrárias (CCA) da Universidade Federal da Paraíba, em Latossolo Vermelho-Amarelo no período de abril a junho de 2000, no município de Areia, PB, foram colhidas e conduzidas ao Setor de Tecnologia de Alimentos do CCA, onde foram debulhadas para obtenção de grãos verdes.

Os grãos obtidos foram selecionados, sendo uma quantidade separada para determinação das características física e química e outra para processamento tipo conserva.

\section{Características químicas}

Para a determinação das características químicas dos grãos frescos e após o processamento, foi determinado o conteúdo de proteína por meio do percentual de nitrogênio total em base seca, segundo método de Kjeldahl, e multiplicado pelo fator 6,25, de acordo com a AOAC (1990).

A umidade determinada nos grãos frescos e após o processamento foi obtida pela matéria seca quando a amostra foi submetida ao aquecimento, em estufa a $105^{\circ} \mathrm{C}$, até peso constante, de acordo com a AOAC (1990). Os grãos frescos e os processados foram triturados obtendo-se um líquido, utilizado na determinação do $\mathrm{pH}$. O pH dos grãos, das salmouras antes e após o processamento térmico e armazenamento dos produtos, foi medido com potenciômetro.

\section{Características físicas}

O peso dos grãos drenados e os volumes das salmouras foram efetuados para todos os lotes de produtos colocados nos frascos. A intensidade de absorção do líquido de acondicionamento nos frascos de vidro, pelos grãos (\%) e a perda de sólidos totais (\%) foram obtidas indiretamente, calculando-se o peso seco e o teor de água (g) antes e após o enchimento.

\section{Delineamento estatístico}

O delineamento estatístico empregado foi inteiramente casualizado com doze tratamentos e duas repetições. Os tratamentos foram representados pelas linhagens e cultivares de feijão caupi. Para comparação entre as médias, utilizou-se o teste de Tukey ao nível de $5 \%$ de probabilidade.

\section{Processamento}

O processamento de todas as linhagens e cultivares ocorreu no dia subseqüente ao da colheita. As operações envolvidas no processamento do feijão caupi verde em conserva estão esquematizadas na Figura 1 (Jerônimo, 2001).

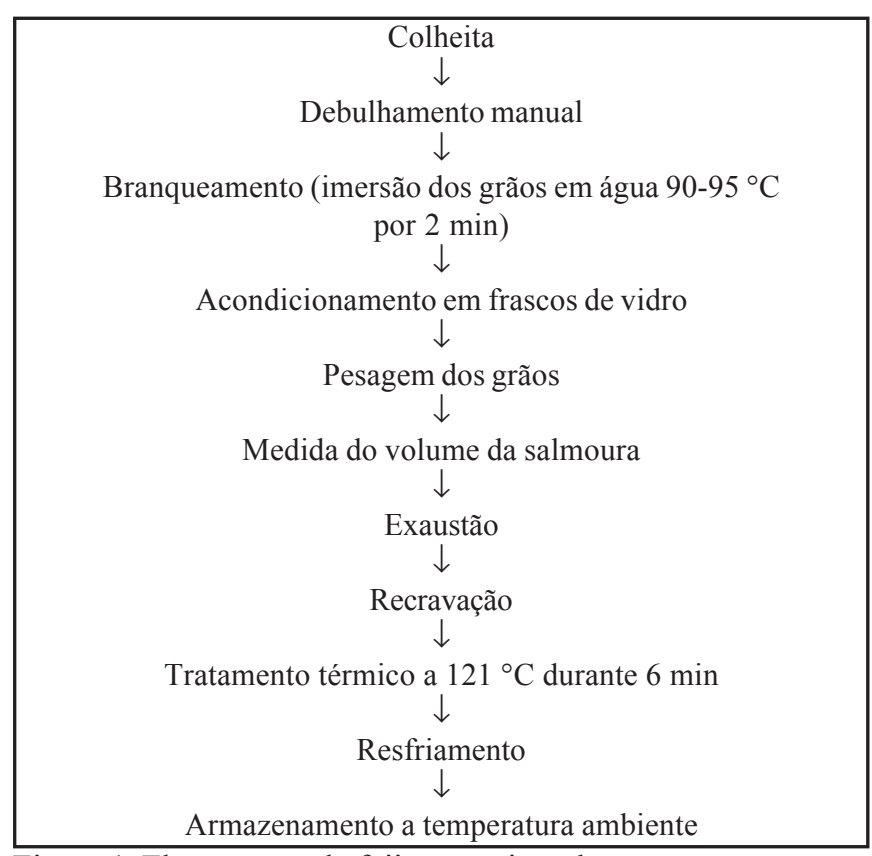

Figura 1. Fluxograma do feijão caupi verde em conserva 
Foram realizados acondicionamentos com 175 a 200 g de feijões e salmoura de $\mathrm{NaCl}$ a 1,5\%, com volume variando de 300 a $350 \mathrm{~mL}$, utilizando-se frascos de vidro com tampas metálicas tipo "twist off", com capacidade para $500 \mathrm{~mL}$.

\section{RESULTADOS E DISCUSSÃO}

A análise de variância revelou diferenças significativas para as linhagens e cultivares, pelo teste Tukey ao nível de 5\% de probabilidade, quanto às características físicas e químicas das diferentes amostras de feijão caupi selecionados e classificados, apresentadas na Figura 2.

Conforme apresentado na Tabela 1, os valores de $\mathrm{pH}$ dos grãos frescos de 6,72 a 6,90, do pH inicial 6,73 e da salmoura final 6,38 a 6,60, classificam o feijão caupi como alimento de baixa acidez, ou seja, fracamente ácidos, necessitando de um processamento térmico de $121^{\circ} \mathrm{C}$ durante $6 \mathrm{~min}$, para garantir a segurança sanitária do produto, principalmente com relação ao esporo do Clostridium botulinum (Germer et al., 1995) pois, efetivamente, esta temperatura é usualmente empregada em alimentos classificados como de baixa acidez (Loey et al.,1994) .

$\mathrm{O}$ pH final dos líquidos de acondicionamento dos grãos verdes das linhagens e cultivares de feijões caupi, apresentou diferenças significativas nos seus $\mathrm{pHs}$ quando comparado com o valores do $\mathrm{pH}$ da salmoura inicial, ocasionado pela diferença do $\mathrm{pH}$ inicial das amostras e com os diferentes percentuais de absorção da salmoura (Tabela 1).

Com relação ao conteúdo médio de proteína, a variação nos grãos frescos foi de 23,16 a $31,30 \%$, enquanto nos grãos processados foi de 22,00 a $27,10 \%$, sendo os grãos frescos superiores e estatisticamente diferentes $(p=0,05)$ dos grãos processados, conforme apresentado na Tabela 1. Esses resultados demonstraram que o processamento conservou, em média, $93 \%$ do total inicial de proteína.

Observa-se, na Tabela 2, o percentual de absorção de água e a perda de sólidos pelos grãos, após o acondicionamento e processamento.

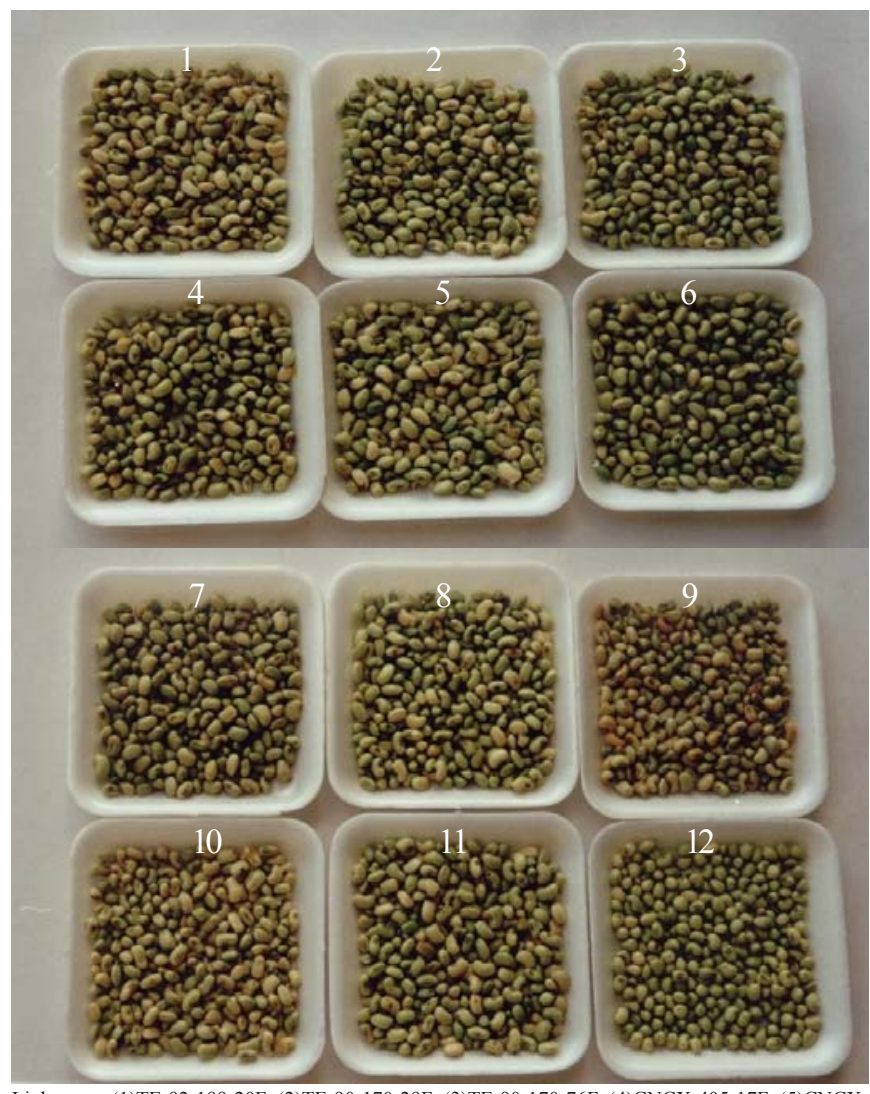

Linhagens: (1)TE-92-199-20F, (2)TE-90-170-29F, (3)TE-90-170-76F, (4)CNCX-405-17F, (5)CNCX409-12-F, (6)TE-90-180-10F, (7)Linguagem Avançada, (8)TE-87-108-6G, (9)TE-90-180-9F, (10)TE90-180-88F e cultivares: (11)IPA-206, (12)BR-02-Bragança

Figura 2. Aparência de grãos verdes frescos de diferentes linhagens e cultivares de feijão caupi

A variação da taxa de absorção de água nas linhagens e cultivares de feijão caupi foi de 56,58 a 87,22\% (Tabela 2); comparando-se com a taxa de absorção em grãos de soja, que variou 25,65 a 57,05\% (Barcelos et al., 1999a) o feijão caupi apresentou elevada taxa de absorção. Com relação ao comportamento das linhagens e das cultivares desse feijão, sobre a absorção de água, verificou-se que a linhagem TE-90-170-76-F apresentou a menor absorção $(56,58 \%)$ diferindo significativa-

Tabela 1. Valores médios* das características físicas e químicas dos grãos frescos e processados

\begin{tabular}{|c|c|c|c|c|c|c|c|}
\hline \multirow{2}{*}{ Amostras } & \multirow{2}{*}{$\begin{array}{l}\text { Peso Inicial } \\
\text { dos Grãos } \\
\text { (g) }\end{array}$} & \multirow{2}{*}{$\begin{array}{l}\text { Peso dos Grãos } \\
\text { Drenados } \\
(\mathrm{g})\end{array}$} & \multirow{2}{*}{$\begin{array}{l}\text { pH dos } \\
\text { Grãos } \\
\text { Frescos }\end{array}$} & \multicolumn{2}{|c|}{$\mathrm{pH}$ da Salmoura } & \multicolumn{2}{|c|}{ Proteína Grão (\%) } \\
\hline & & & & Inicial & Final & Fresco & Processado \\
\hline 1. TE-92-199-20F & 200 & 245 & 6,80 & 6,73 & $6,60 \mathrm{a}$ & $25,33 \mathrm{eA}$ & $24,10 \mathrm{eB}$ \\
\hline 2. TE-90-170-29F & 200 & 250 & 6,90 & 6,73 & $6,58 \mathrm{a}$ & $26,80 \mathrm{dA}$ & $23,36 \mathrm{~dB}$ \\
\hline 3. TE-90-170-76F & 200 & 235 & 6,78 & 6,73 & $6,50 \mathrm{~b}$ & $23,26 \mathrm{fA}$ & $22,00 \mathrm{fB}$ \\
\hline 4. CNCX-405-17F & 200 & 240 & 6,85 & 6,73 & $6,49 \mathrm{~b}$ & $31,30 \mathrm{aA}$ & $24,30 \mathrm{cB}$ \\
\hline 5. CNCX-409-12-F & 200 & 235 & 6,77 & 6,73 & $6,46 \mathrm{c}$ & $23,23 \mathrm{fA}$ & $22,60 \mathrm{eB}$ \\
\hline 6. TE-90-180-10F & 200 & 255 & 6,80 & 6,73 & $6,46 \mathrm{c}$ & $23,16 \mathrm{fA}$ & $22,96 \mathrm{deB}$ \\
\hline 7. Linhagem Avançada & 200 & 240 & 6,82 & 6,73 & $6,44 \mathrm{c}$ & $30,60 \mathrm{bA}$ & $27,10 \mathrm{aB}$ \\
\hline 8. TE-87-108-6G & 200 & 235 & 6,76 & 6,73 & $6,40 \mathrm{~d}$ & $23,33 \mathrm{fA}$ & $22,90 \mathrm{eB}$ \\
\hline 9. TE-90-180-9F & 170 & 210 & 6,80 & 6,73 & $6,39 \mathrm{~d}$ & $28,73 \mathrm{cA}$ & $25,70 \mathrm{bB}$ \\
\hline 10. TE-90-180-88F e cultivares & 185 & 220 & 6,80 & 6,73 & $6,38 \mathrm{~d}$ & $28,83 \mathrm{cA}$ & $25,40 \mathrm{bB}$ \\
\hline 11. IPA-206 & 200 & 240 & 6,81 & 6,73 & $6,38 \mathrm{~d}$ & $25,23 \mathrm{eA}$ & $25,80 \mathrm{bB}$ \\
\hline 12. BR-02-Bragança & 200 & 240 & 6,72 & 6,73 & $6,38 \mathrm{~d}$ & $23,30 \mathrm{fA}$ & $22,90 \mathrm{eB}$ \\
\hline DMS-Coluna & & & & & 0,028 & 0,40 & 0,40 \\
\hline DMS-Linha & & & & & & 0,24 & 0,24 \\
\hline $\mathrm{CV}(\%)$ & & & & & 0,15 & 0,58 & 0,58 \\
\hline
\end{tabular}

"Médias seguidas de mesmas letras minúsculas nas colunas e maiúsculas nas linhas, não diferem significativamente pelo teste de Tukey em $5 \%$ de probabilidade 
Tabela 2. Absorção do líquido de acondicionamento e perda de sólidos totais pelos grãos verdes de linhagens e cultivares de feijão caupi processados tipo conserva*

\begin{tabular}{|c|c|c|c|c|c|c|}
\hline \multirow{2}{*}{ Amostras } & \multicolumn{2}{|c|}{ Grãos Frescos } & \multicolumn{4}{|c|}{ Grãos Processados } \\
\hline & Peso (g) & Umidade (\%) & Peso $(g)$ & Umidade (\%) & Absorção de Água (\%) & Perda de Sólidos (\%) \\
\hline 1. TE-92-199-20F & 200 & 62,67 & 245 & 74,68 & $77,20 \mathrm{f}$ & $12,61 \mathrm{~h}$ \\
\hline 2. TE-90-170-29F & 200 & 65,96 & 250 & 74,56 & $80,02 \mathrm{~d}$ & $6,58 \mathrm{j}$ \\
\hline 4. $\mathrm{CNCX}-405-17 \mathrm{~F}$ & 200 & 66,11 & 240 & 77,08 & $77,84 \mathrm{e}$ & $18,83 \mathrm{~g}$ \\
\hline 5. CNCX-409-12-F & 200 & 64,47 & 235 & 77,14 & $73,67 \mathrm{i}$ & $24,72 \mathrm{c}$ \\
\hline 6. TE-90-180-10F & 200 & 63,35 & 255 & 74,76 & $87,22 \mathrm{a}$ & $12,21 \mathrm{~h}$ \\
\hline 8. TE-87-108-6G & 200 & 66,20 & 235 & 74,75 & $63,97 \mathrm{k}$ & $12,21 \mathrm{~h}$ \\
\hline 9. TE-90-180-9F & 170 & 61,01 & 210 & 75,19 & $81,75 \mathrm{c}$ & $21,39 \mathrm{f}$ \\
\hline 10. TE-90-180-88F e cultivares & 185 & 60,15 & 220 & 73,66 & $68,86 \mathrm{j}$ & $26,81 \mathrm{~b}$ \\
\hline 11. IPA-206 & 200 & 61,69 & 240 & 75,66 & $75,95 \mathrm{~g}$ & $23,73 \mathrm{~d}$ \\
\hline 12. BR-02-Bragança & 200 & 58,45 & 240 & 78,05 & $84,74 \mathrm{~b}$ & $36,59 \mathrm{a}$ \\
\hline DMS & & & & & 0,42 & 0,16 \\
\hline
\end{tabular}

"Médias seguidas de mesma letra, nas colunas, não diferem estatisticamente pelo teste de Tukey em $5 \%$ de probabilidade

mente dos genótipos. Este valor se semelhou à taxa média de absorção de água pelos grãos do feijão-guandu, em torno de $57 \%$ (Barcelos et al.,1999b).

Nas amostras estudadas, as perdas de sólidos variaram de 6,58 a $36,59 \%$. A menor perda de sólidos (\%) ocorreu com as amostras TE-90-170-29F e TE-90-170-76F, diferindo significativamente das demais amostras, principalmente com a de número BR-02-Bragança. A diferença encontrada nos valores de absorção de água e perda de sólidos entre as amostras deve-se, provavelmente, à origem dos grãos das diferentes linhagens e cultivares e ao fato dos mesmos não terem sido obtidos com o mesmo período de antese, o que lhe confere grau de maturação diferenciado. A perda de sólido não se correlacionou com os valores de perda de proteína encontrados na Tabela 1.
Constatou-se, na Tabela 2, que a umidade dos grãos frescos apresenta-se elevada, variando de 58,45 a $66,20 \%$, demonstrando que os grãos de feijão se apresentaram no estádio verde considerado no início da maturidade fisiológica.

A Figura 3 apresenta a aparência dos grãos de feijão caupi verde das dez linhagens e duas cultivares e a cor do líquido de acondicionamento, após o processamento em frasco de vidro.

As amostras TE-87-108-6G, Linhagem Avançada, TE-90-18088F e TE-92-199-20F, apresentaram, através da observação visual, em ordem decrescente, melhor aparência quanto à coloração, após o processamento dos grãos de cor verde acinzentado, e líquido de acondicionamento, muito semelhante às variedades de feijão caupi verde consumido na região.

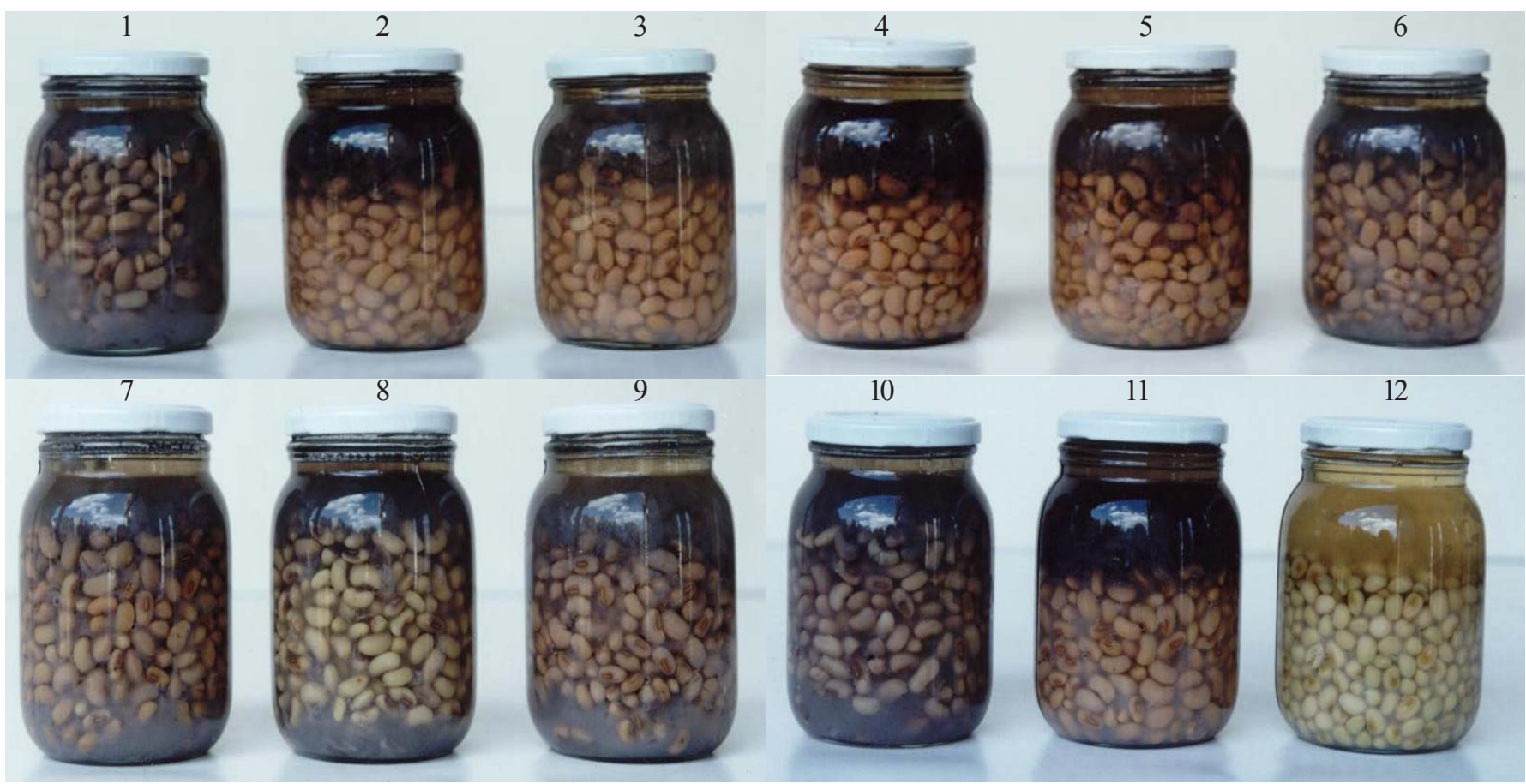

Linhagens: (1)TE-92-199-20F, (2)TE-90-170-29F, (3)TE-90-170-76F, (4)CNCX-40517F, (5)CNCX-409-12-F, (6)TE-90-180-10F, (7)LINHAGEM AVANÇADA, (8)TE-87-108-6G, (9)TE-90-180-9F, (10)TE-90180-88F e cultivares: (11)IPA-206, (12)BR-02-BRAGANÇA

Figura 3. Aparência do grão de feijão caupi verde de diferentes linhagens e cultivares, em conserva 
A cultivar BR-02-Bragança (Amostra 12) apresentou coloração dos grãos amarelo esverdeado e o líquido de acondicionamento de cor amarelado, diferenciando-se das demais linhagens e cultivar IPA-206.

A coloração apresentada pelos grãos das amostras TE-90170-29F, TE-90-170-76F, CNCX-405-17F, CNCX-409-12-F, TE-90-180-10F, TE-90-180-9F e IPA-206, foi marrom, com aparência agradável confundindo-se, no entanto, com amostras de feijão Phaseolus vulgaris. A coloração do líquido de acondicionamento (Figura 4) indica que, na maioria das amostras, ocorreu intenso escurecimento devido, provavelmente, à ação das polifenoloxidases sobre os polifenóis (tanino).

O aparecimento de coloração parda ou marrom surge quando o tecido vegetal sofre uma ação física e a estrutura

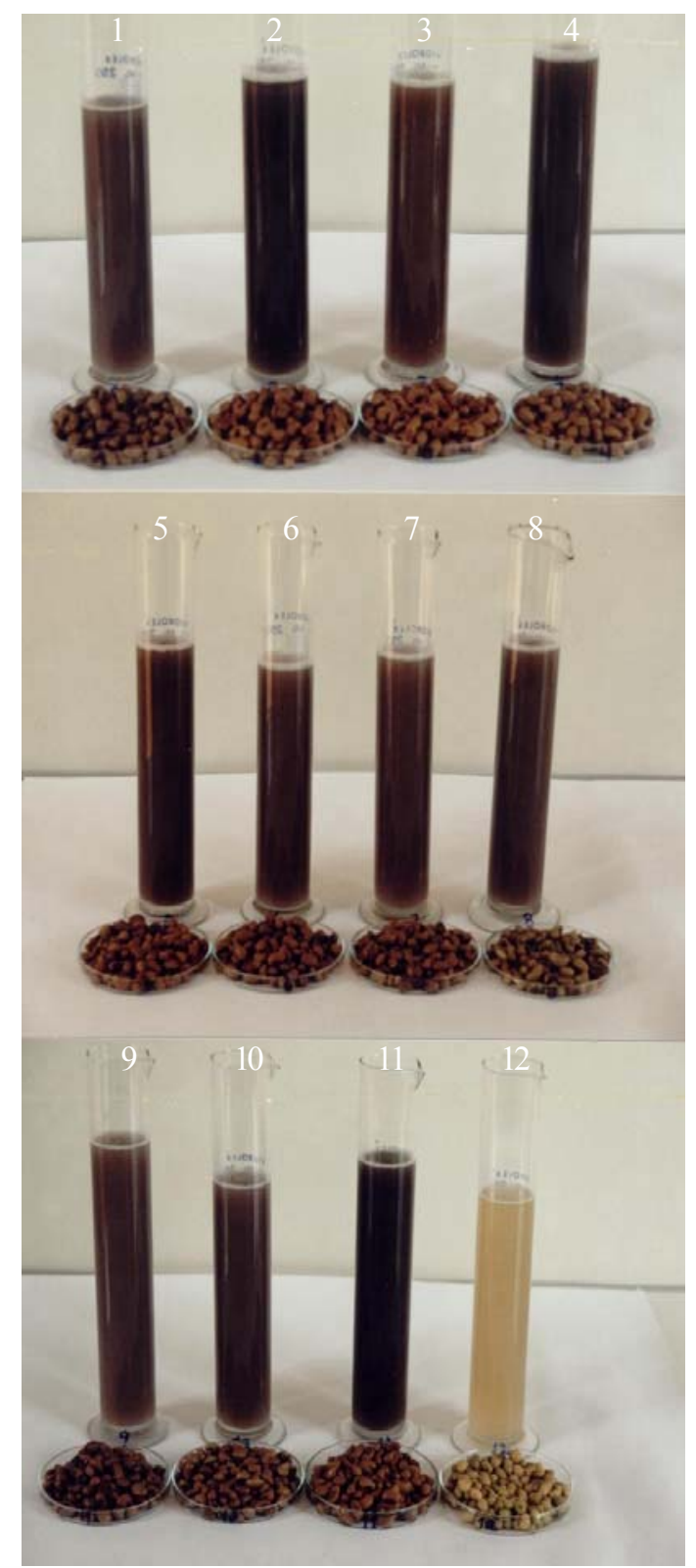

Linhagens (1)TE-92-199-20F, (2)TE-90-170-29F, (3)TE-90-170-76F, (4)CNCX-405-17F, (5)CNCX409-12-F, (6)TE-90-180-10F, (7)LINHAGEM AVANCADA, (8)TE-87-108-6G, (9)TE-90-180-9F, (10)TE-90-180-88F e cultivares (11)IPA-206, (12)BR-02-BRAGANÇA

Figura 4. Intensidade e tonalidade da cor do líquido de acondicionamento (salmoura) e dos grãos verdes de linhagens e cultivares de feijão caupi, em conserva celular é rompida, a enzima polifenoloxidase liberada oxida os compostos fenólicos formando quinonas, as quais são coloridas e têm papel importante na formação das melaninas de coloração escura. Os compostos naturais mais sujeitos a essas oxidações são catecol, tirosina, ácido clorogênico, ácido gálico, hidroquinonas e um grande número de antocianinas e flavonóides (Iaderoza \& Baldini, 1991).

O líquido de acondicionamento da Amostra 12 apresentouse completamente diferente das demais, com intensa cor amarelada, evidenciando a necessidade de mais estudos sobre esta cultivar (BR-02-Bragança).

\section{CONCLUSÕES}

1. As linhagens que apresentaram características aparentes classificadas neste estudo, em condições mais adequadas ao processamento em ordem decrescente, foram as amostras TE-87-108-6G, Linhagem avançada, TE-90-180-88F e TE-92199-20F.

2. A cor verde dos grãos manteve-se após o processamento, apenas nas linhagens: TE-87-108-6G, Linhagem avançada, TE-90-180-88F e TE-92-199-20F.

3. O processo tipo conserva provoca pequeno decréscimo de proteína total dos grãos das diferentes linhagens e cultivares conservando, em média, $93 \%$.

4. Não houve correlação para todas as amostras, no que diz respeito ao percentual de absorção de água e de perda de sólidos.

5. Considerando-se a tecnologia empregada e os resultados obtidos, o feijão caupi verde não sofreu grandes alterações e manteve suas boas características na obtenção de seus produtos.

\section{LITERATURA CITADA}

Abbatemarco, C.; Ramaswamy, H.S. End-over-end thermal processing of canned vegetables: effect on texture and color. Food Research International, Essex, v.27, n.4, p.327-334, 1994. AOAC - Association of Official Analytical Chemists. 15.ed. Washington: Official methods of analysis. 1990. $2 \mathrm{v}$.

Barcelos, M.F.P.; Tavares, D.Q.; Silva, M.A.A.P.; Miranda, M.A.C. Ensaio tecnológico e sensorial de soja (Glycine max (L.) Merrill) enlatados em estádios verdes e no estádio da maturação de colheita. Ciência e Tecnologia de Alimentos, Campinas, v.19, n.1, p.46-58, 1999a.

Barcelos, M. F. P. ; Tavares, D.Q.; Silva, M.A.A.P.; Miranda, M. A. C.; Germer, S.P.M. Aspectos tecnológicos e sensoriais do guandu (Cajunus cajan (L.) Millsp.) enlatados em diferentes estádios de maturação. Ciência e Tecnologia de Alimentos, Campinas, v.19, n.1, p.73-83, 1999b.

Calegari, A. Leguminosas para adubação verde de verão no Paraná. Londrina: IAPAR, 1995. p.115. Circular Técnico, 80

Cazetta, J.O.; Kanesiro, M.A.B.; Faleiro, R.R.S.; Durigan, J.F. Comparação de aspecto químico e tecnológicos de grãos verdes e maduros de guandu com os de feijão-comum e ervilha. Alimentos e Nutrição, São Paulo, v.6, p.39-53, 1995. 
EMBRAPA - Empresa Brasileira de Pesquisa Agropecuária. Industrialização do feijão pode aumentar consumo per capita. Goiânia: EMBRAPA Feijão e Arroz. 1997. 4p.

Germer, S.P.M.; Moura, S.C.S.R.; Leitão, M.F.F.; Junqueira, V.C.A.; Teixeira Neto, R.O.; Goncalves, J.R., Jardim, D.C.P.; Vital, A. A. Princípios de esterilização de alimentos. 2 ed. Campinas: ITAL, 1995, p.123. Manual Técnico,10

Iaderoza, M.; Baldini, V.L.S. A importância da análise enzímica em alimentos. In: Enzimas e a qualidade de vegetais processados. Campinas: ITAL, 1991. p. 37-51.

Islam, M.N.; Lea, R.A. Effect of maturity on the nutrient content and the canning Quality of emerald soy bean. Journal of Food Science, Chicago, v. 44, n.1, p.204-212, 1979.

Jerônimo, E.S. Cararcterísticas físicas e químicas de grãos verdes de linhagens e cultivares de feijão caupi (Vigna unguiculata L. Walp.) para processamento tipo "conserva". Areia: UFPB/CCA, 2001.32p. Monografia Graduação
Loey, A.V.; Fransis, A.; Hendrickx, M.; Maesmans, G.; Noronha, J.; Tobback, P. Optimizing thermal process for canned. White beans in water cascading retorts. Journal of Food Science, Chicago, v.40, n.3, p.828-832, 1994.

Parsi-Ros, O.; Rodriguez-Sosa, E.J.; Cruz-Cay, J.; CintronMuñoS, M.E. Processing and nutritional contents of canned and fresh pigeon peas (Cajanus cajan (L.)). The Journal of Agriculture of the University Puerto Rico, Rio das Piedras, v.71,n.1, p.33-41, 1987.

Quast, D.C.; Silva, S.D. Temperature dependence of the cooking rate of dry legumes. Journal of Food Science, Chicago, v.42, n.2, p.370-374, 1977.

Sellschop. J.P.Ferns. Cowpeas. Vigna unguiculata (L.) Walp. Field Crop Abstract, v.15, n.4, p.259-266, 1962.

Vieira, C. Leguminosas de grãos: importância na agricultura e na alimentação humana.Informe Agropecuário, Belo Horizonte, v.16, n.174, p.5-11, 1992. 